\title{
C- and L-band multi-temporal polarimetric signatures of crops
}

\author{
Skriver, Henning; Nielsen, Flemming; Thomsen, Anton
}

Published in:

Proceedings of the International Geoscience and Remote Sensing Symposium

Publication date:

1996

Document Version

Publisher's PDF, also known as Version of record

Link back to DTU Orbit

Citation (APA):

Skriver, H., Nielsen, F., \& Thomsen, A. (1996). C- and L-band multi-temporal polarimetric signatures of crops. In Proceedings of the International Geoscience and Remote Sensing Symposium: Remote Sensing for a Sustainable Future (Vol. Volume 3, pp. 1766-1768). IEEE.

\section{General rights}

Copyright and moral rights for the publications made accessible in the public portal are retained by the authors and/or other copyright owners and it is a condition of accessing publications that users recognise and abide by the legal requirements associated with these rights.

- Users may download and print one copy of any publication from the public portal for the purpose of private study or research.

- You may not further distribute the material or use it for any profit-making activity or commercial gain

- You may freely distribute the URL identifying the publication in the public portal

If you believe that this document breaches copyright please contact us providing details, and we will remove access to the work immediately and investigate your claim. 


\title{
C- and L-Band Multi-Temporal Polarimetric Signatures of Crops
}

\author{
Henning Skriver ${ }^{1}$, Flemming Nielsen ${ }^{2}$, and Anton Thomsen ${ }^{2}$ \\ ${ }^{1}$ Danish Center for Remote Sensing, Dept. Electromagnetic Systems \\ Technical University of Denmark, Building 348, DK-2800 Lyngby, Denmark \\ Phone: +45 458814 44, Fax: +45 4593 1634, E-mail: hs@emi.dtu.dk \\ ${ }^{2}$ Danish Institute of Plant and Soil Sciences \\ Research Center Foulum, DK-8830 Tjele, Denmark
}

\begin{abstract}
Polarimetric SAR-data of agricultural fields have been acquired by the Danish polarimetric SAR (EMISAR ${ }^{1}$ ) during a number of missions ${ }^{2}$ at the Danish test site Foulum during 1994 and 1995. EMISAR has operated in a fully polarimetric mode at C-band since the fall of 1993 and at L-band since the beginning of 1995. The SAR system is installed on a Danish Air Force Gulfstream aircraft, and a significant amount of polarimetric SAR data have been acquired on various missions. Polarimetric parameters for a number of different agricultural crops are shown, and the advantage of having polarimetric, multi-frequency, and multi-temporal data for crop discrimination is clearly seen.
\end{abstract}

\section{INTRODUCTION}

A research and development project initiated in 1986 at the Department of Electromagnetic Systems (EMI) of the Technical University of Denmark resulted in a C-band VVpolarized airborne SAR first flown in 1989 [1]. The Danish airborne polarimetric SAR (EMISAR) has since then been extended to an L- and C-band fully polarimetric and interferometric SAR [2]. The polarimetric extension of the system has been co-sponsored by the EU's Joint Research Centre (JRC). The EMISAR is used for scientific experiments conducted by the Danish Center for Remote Sensing (DCRS) which was established early 1994 at EMI by the Danish National Research Foundation, and it is expected to be utilized by JRC for its European Airborne Remote Sensing Campaign (EARSEC). Also, EMISAR has been used for the European Multisensor Airborne Campaign (EMAC) arranged by ESA.

The SAR system is installed on a Danish Air Force Gulfstream. The SAR system is normally operated from an altitude of approximately $12.500 \mathrm{~m}$, the spatial resolution is $2 \mathrm{~m}$ by $2 \mathrm{~m}$, the ground range swath is approximately $12 \mathrm{~km}$ and typical angles of incidence range from $35^{\circ}$ to $60^{\circ}$. The processed data from this system are fully

\footnotetext{
${ }^{1}$ Development of the EMISAR has been co-sponsored by the Thomas B. Thriges Foundation, the Danish Technical Research Council (STVF), the Royal Danish Air Force, the Technical University of Denmark, and the Joint Research Centre.

${ }^{2}$ The data acquisitions, data processing and data interpretation have been sponsored by the Danish National Research Foundation and the Danish Space Board.
}

calibrated by using an internal calibration and a test area is equipped with a number of reference targets thus enabling the verification of system performance. The radiometric calibration is better than $\pm 0.5 \mathrm{~dB}$, and the channel imbalance is less than $\pm 0.5 \mathrm{~dB}$ in amplitude and $\pm 5^{\circ}$ in phase. The cross polarisation contamination is generally suppressed by more than $30 \mathrm{~dB}$.

The DCRS conducts research in collaboration with science partners within areas related to remote sensing techniques and Earth science, such as agriculture, environment, geology, glaciology, hydrology and sea ice. The research within agriculture, i.e. on crop monitoring and soil moisture mapping, is carried out in co-operation with Research Center Foulum (RCF). The RCF is a research centre under the Danish Ministry of Agriculture, with intensively monitored farm land, ideally suited for studying the application of remote sensing to agriculture. The research is primarily aiming at studying the application of radar remote sensing techniques to monitor agricultural crops, biomass, and soil physics. The primary observational technique is SAR polarimetry, and results from this study will be presented in this paper.

\section{DATA ACQUISITION}

The test site used for the agriculture study is located in the northern part of Jutland around RCF at Foulum. At $\mathrm{RCF}$, spectral reflectance measurements in the visible and near infra-red spectral bands are routinely used to monitor biomass and canopy structure (leaf-area-index, foliage distribution and orientation). The primary instruments are mast mounted and portable dual band (visible red and near infra-red) radiometers. Digital analysis of false-color aerial photography is used for field variability mapping. Instrumentation and laboratory facilities are also available for the measurement of water content of canopy elements, soil composition, micro relief, and water content.

A large number of acquisitions with both the C- and Lband polarimetric SAR was carried out in 1995, for instance on March 22 (L-band), March 24 (C-band), April 27 (C-band), June 8 (L-band), and July 4 (C- and L-band). The data acquisitions have been co-ordinated with extensive in-situ measurement campaigns, where e.g. soil moisture, soil roughness, a multitude of plant parameters and crop types were measured. 


\section{VEGETATION SIGNATURES}

It is well known that the canopy development of different crops with time causes variation of the backscatter, and it is the basis for e.g. multi-temporal classification of ERS-1 SAR data (e.g. [3]). Also, for polarimetric SAR data multi-temporal acquisitions may contain additional and important information (see e.g. [4]). Below examples of backscatter coefficients for different crop types will be shown, that is winter wheat, winter barley, winter rape, and spring barley.

The polygons picked for the crop types contain at least 2000 pixels, where the pixels are sampled with $1.5 \mathrm{~m}$ pixel spacing. The pixels are of course correlated, and using homogenous areas in the image, the equivalent number of looks for an 2000 pixel area is estimated to at least 300 . This results in a standard deviation for the backscatter coefficients due to the speckle noise of less than $0.2 \mathrm{~dB}$. The variance caused by the speckle noise will consequently have a very small effect on the results from the polygons used, and it is ignored below.

The polygons are picked in the full range of incidence angles from about $39^{\circ}$ to $58^{\circ}$. The polygons are then grouped according to their incidence angle in $4^{\circ}$ intervals, and the mean and standard deviation are computed for each of these intervals, so that error bars may be estimated. Examples of these results are shown in Figs. 1 and 2, where the angular dependence of the $\gamma_{\mathrm{vV}}$ backscatter coefficient for the $\mathrm{L}$ - and C-band acquisitions in March is shown. The $\gamma$ backscatter coefficient is used because it has a slightly weaker dependence on the incidence angle than the $\sigma$ backscatter coefficient. For the actual incidence angle interval the decrease with incidence angle is about $1.5 \mathrm{~B}$ larger for $\sigma$ than for $\gamma$. In a crop discrimination application the weaker dependence is an advantage, because fewer classes are necessary to cope with the variation.

The largest variation between near- and far-range is observed for these early spring acquisitions (about $4 \mathrm{~dB}$ at $\mathrm{L}$-band and about $2 \mathrm{~dB}$ at C-band), whereas the variation is well below $2 \mathrm{~dB}$ for the later acquisitions. These observations correspond with the fact that the backscattering in the early spring is dominated by surface scattering from the bare fields, whereas volume scattering from the vegetation is contributing at the later acquisitions. Furthermore, we have the largest variation at L-band because the same surface appears rougher at C-band than at L-band.

As mentioned above the incidence angle dependence is weak especially for the larger incidence angles. Therefore, fields with incidence angles larger than $45^{\circ}$ are used to compute the multi-temporal signatures and their standard deviation. The multi-temporal $\gamma_{V V}$ backscatter coefficients for L- and C-band are shown in Figs. 3 and 4, respectively, and the multi-temporal $\gamma_{\mathrm{XP}}$ backscatter coefficients for Land $\mathrm{C}$-band are shown in Figs. 5 and 6 , respectively. The $\gamma_{X P}$ backscatter coefficient is computed by averaging the scattering matrix elements $\mathrm{S}_{\mathrm{HV}}$ and $\mathrm{S}_{\mathrm{VH}}$ for thermal noise reduction, where reciprocity has been implied.

We observe, that the variation indicated by the error bars is relatively large, especially at the early spring acquisitions. The standard deviation is from 2 to $3 \mathrm{~dB}$ for the latter acquisitions, probably caused by the sensitivity of the backscattering to the plowing direction. For the later acquisitions the standard deviation is smaller, e.g. less than $1 \mathrm{~dB}$ in most of the cases, probably caused by the backscatter contribution from the vegetation. The standard deviation for the L-band data is slightly larger than for the C-band data.

All the curves for the spring barley, the winter barley and the winter wheat are constant or decreasing from the March to the May acquisition and then increasing for the later acquisitions. The increase is correlated with the measurements of the Leaf Area Index (LAI) (c.f. [5]), where the LAI increases from 1.5 at Julian Day 137 to 3.3 at Julian Day 178. We observe a more distinct increase at Lband. The backscattering from the winter rape differs significantly from the others, because of the very different structure and larger biomass.

The importance of multi-temporal acquisitions for classification applications is clearly seen from the results. Using the acquisitions in May and in July of the C-XP channel it will be possible to discriminate between the crops. Furthermore, it is obvious that the discrimination capability is larger for the C-band than for the L-band.

\section{CONCLUSIONS}

Multi-temporal and multi-frequency vegetation backscatter results measured by the Danish L- and C-band polarimetric SAR have been presented. We observed a relatively large variation of the backscattering from fields at approximately the same incidence angle. This variation is probably coarse by the sensitivity of the backscattering to e.g. the plowing and sowing directions, and the local incidence angle. The multi-temporal signatures showed correlation with LAI and thereby biomass. Finally, C-band has larger discrimination capability than L-band.

\section{REFERENCES}

[1] Madsen, S.N., E. L. Christensen, N. Skou, and J. Dall: The Danish SAR System: Design and Initial Tests, IEEE Trans. Geosc. Rem Sens., vol. 29,1991 , pp. 417-476.

[2] Christensen, E. L., J. Dall, N. Skou, J. Granholm, K. Woelders, and S.N. Madsen,: EMISAR: $C$ - and L-band Polarimetric and Interferometric SAR, Proc. IGARSS 96, this issue.

[3] Schotten, C. G. J., W. W. L. van Rooy, and L. L. F Janssen: Assessment of the capabilities of multi-temporal ERS-1 SAR data to discriminate between agricultural crops, Int. J. Remote Sensing, 1995, vol. 16, pp. 2619-2637.

[4] Baronti, S., F. Del Frate, P. Ferrazzoli, S. Paloscia, P. Pampaloni, and G. Schiavon: SAR polarimetric features of agricultural areas, Int. J. Remote Sensing, 1995, vol. 16, pp. 2639-2656.

[5] Ulaby, F. T., C.T. Allen, G. Eger III, and E. Kanemasu, 1984, Relating the Microwave Backscattering Coefficient to Leaf Area Index, Remote Sening Environ., vol. 14, pp. 113-133. 


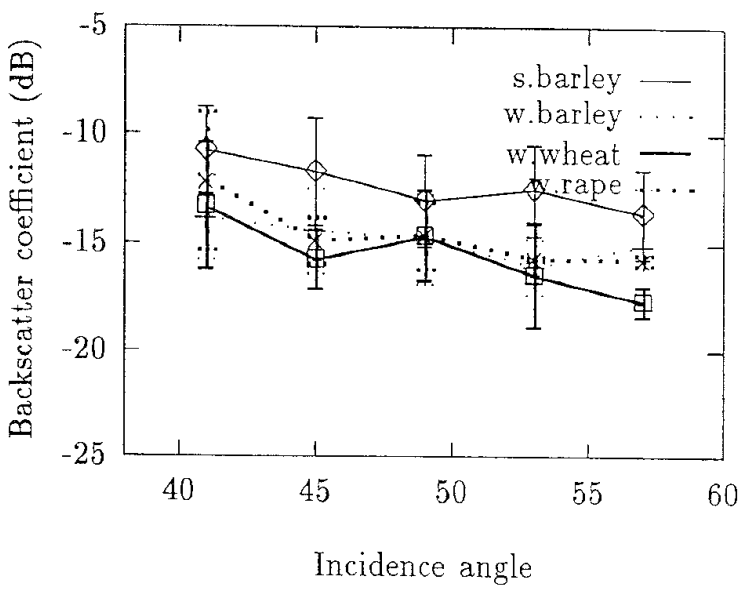

Fig. 1 The $\gamma_{\mathrm{vV}}$ backscatter coefficient for L-band acquired March 22, 95.

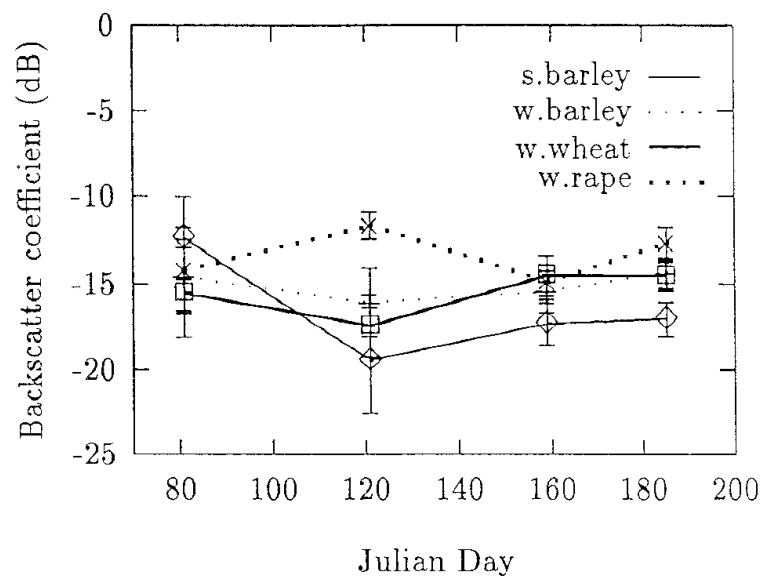

Fig. 3 The multi-temporal $\gamma_{\mathrm{V}}$ backscatter coefficient for L-band acquired 95 .

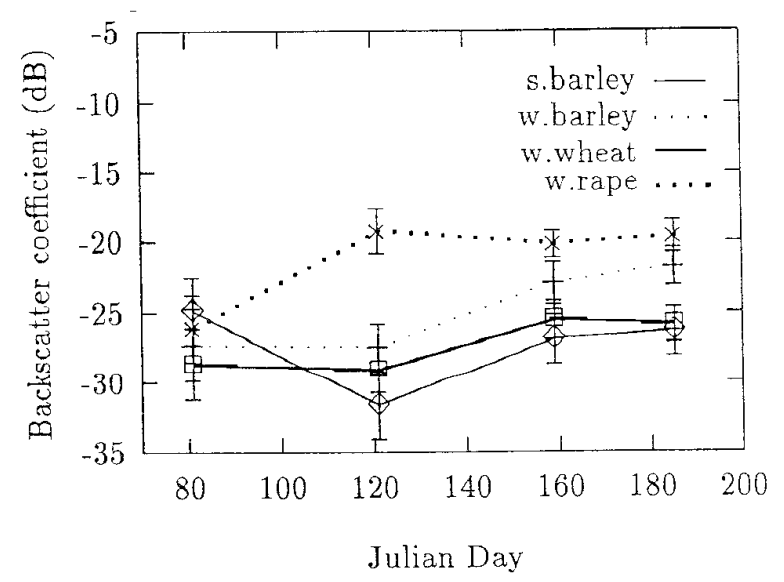

Fig. 5 The multi-temporal $\gamma_{\mathrm{XP}}$ backscatter coefficient for L-band acquired 95 .

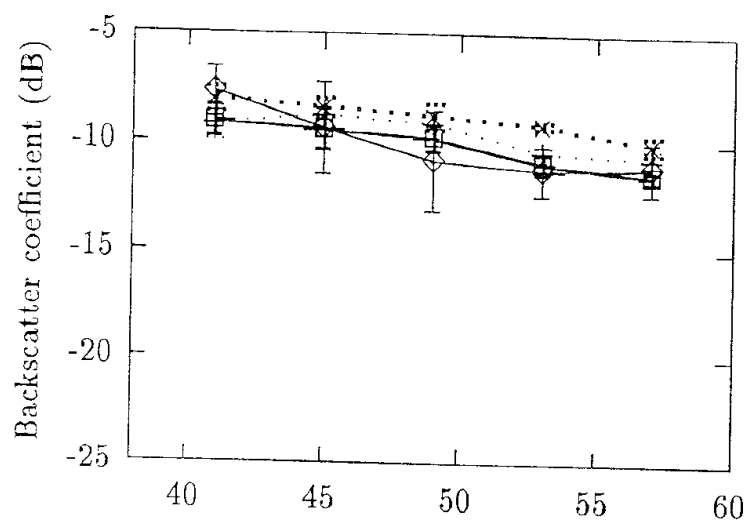

Incidence angle

Hig. 2 ine $\gamma_{V V}$ backscatter coefficient for C-band acquired March 24, 95.

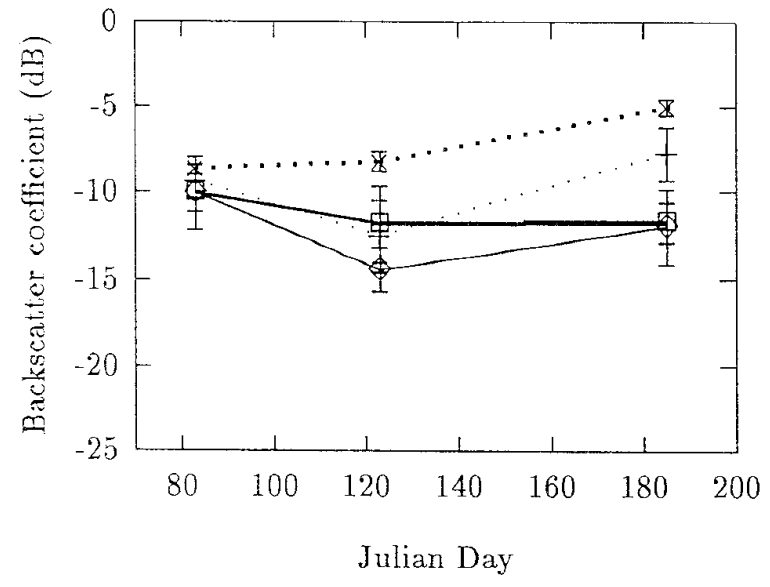

Fig. 4 The multi-temporal $\gamma_{v v}$ backscatter coefficient for C-band acquired 95 .

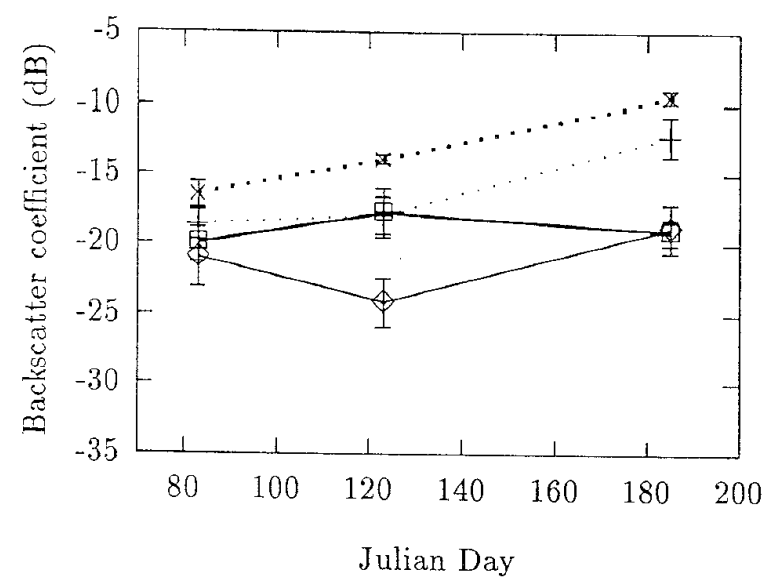

Fig. 6 The multi-temporal $\gamma_{\mathrm{XP}}$ backscatter coefficient for $\mathrm{C}$-band acquired 95 . 